\section{F. Chmilewsky', C. Jeanneau', P. Laurent ${ }^{1}$, M. Kirschfink ${ }^{2}$, and I. About ${ }^{\text {* }}$}

${ }^{1}$ Aix-Marseille Université, CNRS, ISM UMR 7287, 13288, Marseille cedex 09, France; and ${ }^{2}$ Institut für Immunologie, Universität Heidelberg Im Neuenheimer Feld 305 D-69120 Heidelberg, Germany; *corresponding author, imad.about@ univ-amu.fr

\section{ABSTRACT}

It recently became evident that activation of the complement system also contributes to tissue regeneration after infection/injury. The complementderived fragment $\mathrm{C} 5 \mathrm{a}$ induces vascular modifications and attracts cells expressing its receptor $(\mathrm{C} 5 \mathrm{aR} /$ CD88) to the site of infection and tissue injury. Besides inflammatory cells, various tissue cells express this receptor. We hypothesized that pulp progenitor cells, being exposed to local complement activation in caries lesions, may respond to C5a via the C5aR. Our work aimed at evaluating the ability of $\mathrm{C} 5 \mathrm{a}$ to induce pulp progenitor cell migration that may link complement activation to dentin regeneration. Immunofluorescence analysis of third molar pulp sections showed perivascular localization of the mesenchymal stem cell markers STRO-1 and C5aR. RT-PCR on STRO-1-sorted pulp progenitor cells, co-expressing both STRO-1 and $\mathrm{C} 5 \mathrm{aR}$, revealed high $\mathrm{C} 5 \mathrm{aR}$ mRNA levels. Experiments with the C5aR antagonist W54011 revealed that $\mathrm{C} 5$ a specifically bound to progenitor cells via $\mathrm{C} 5 \mathrm{aR}$, inducing their selective migration toward the C5a gradient. Since we could also demonstrate C5b-9 formation by immunohistochemistry in carious teeth, our findings suggest that, upon local complement activation, C5a induces pulp progenitor cell migration, which may be critical in initiating the regenerative process after dentin/ pulp injury.

KEY WORDS: pulp biology, regenerative medicine, stem cell(s), odontoblast(s), complement, chemotaxis.

\title{
Pulp Progenitor Cell Recruitment is Selectively Guided by a C5a Gradient
}

\section{INTRODUCTION}

Complement activation plays a major role in the inflammatory response following infections and traumatic injury. In the dental pulp, such inflammatory reactions occur after carious injuries, leading to odontoblast apoptosis/ destruction (Mitsiadis et al., 2008). The damaged dentin is then replaced by a protective reparative dentin secreted by a new generation of odontoblastic cells (Fitzgerald et al., 1990). The reparative dentin secretion is a complex process requiring the presence of responsive pulp progenitor cells as well as appropriate signals for their recruitment and differentiation. The presence of these cells in the pulp has been shown in many studies using different approaches and surface markers (Gronthos et al., 2002; Iohara et al., 2008; Téclès et al., 2008). Although other localizations cannot be excluded, some dental stem cells (DPSCs) reside in the perivascular area (Shi and Gronthos, 2003). When the dentin/pulp tissue is damaged, they are recruited from their niches to the injury site (Téclès et al., 2005). Surprisingly little is known about the mechanisms that mediate DPSC migration. There is compelling evidence that, in severe carious lesions, DPSCs can be activated by growth factors, released from the carious dentin acidic dissolution (Smith et al., 1994; Sloan and Smith, 1999). However, it has been demonstrated that, after surgical pulp amputation, healing can occur with hard-tissue formation in germ-free animals independent of dentin-derived growth factors (Tsuji et al., 1987; Inoue and Shimono, 1992; Téclès et al., 2008). This suggests that other mechanisms may be involved in this process and motivated us to seek possible inflammationassociated chemoattractants that may induce progenitor cell migration.

The coagulation and complement systems are powerful plasma cascades that play essential roles in inflammation and immunity. Complement is mainly activated by infectious agents and traumatic injuries (Ehrnthaller et al., 2011), leading to the production of various inflammatory mediators such as $\mathrm{C} 3 \mathrm{a}$ and C5a and to the formation of a cytolytic membrane attack complex (C5b-9) on the pathogen surface (Cruvinel et al., 2010). The biologically active anaphylatoxin C5a exerts its action through the G-protein-coupled C5a receptor (C5aR/ CD88). During the inflammatory process, C5a induces blood vessel vasodilation and the recruitment of C5aR-expressing leukocytes. These cells migrate following a $\mathrm{C} 5$ a concentration gradient toward the inflammatory site (Klos et al., 2009). However, in addition to various immune cells, several nonimmune cells express $\mathrm{C} 5 \mathrm{aR}$, such as endothelial cells, astrocytes, cells from skin, intestine, heart, and human mesenchymal stem cells (Klos et al., 2009; Schraufstatter et al., 2009). This receptor is also expressed by cells involved in the mineralization process, such as osteoblasts (Ignatius et al., 2011).

Our objective was to investigate if pulp progenitor cells express C5aR, rendering them responsive to complement activation by migrating to a $\mathrm{C} 5 \mathrm{a}$ gradient. 
A

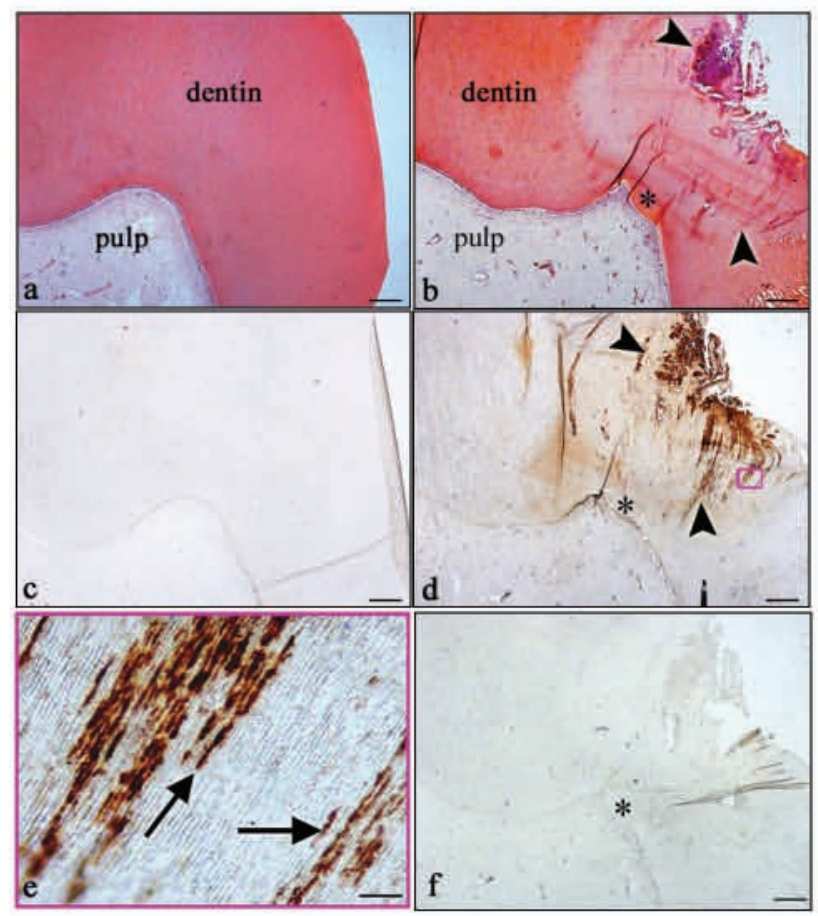

B

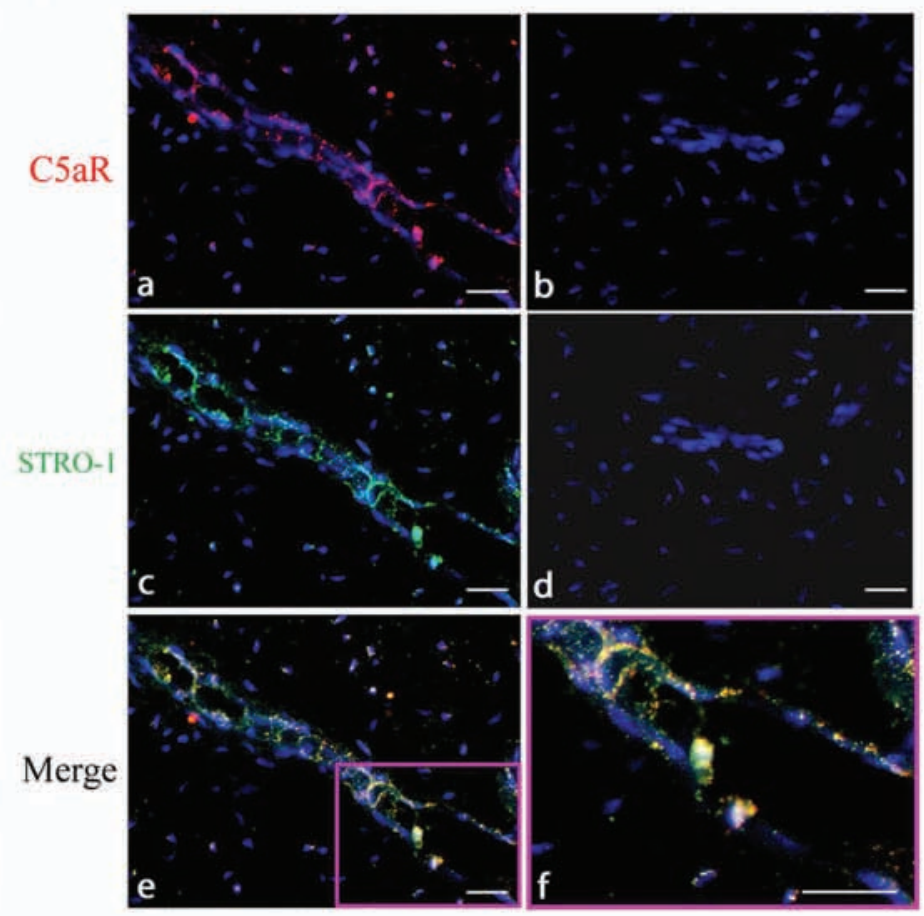

Figure 1. Complement activation and expression of C5aR and STRO-1 in vivo. (A) Immunohistochemistry was used to investigate complement activation through the formation of the cytolytic membrane attack complex (C5b-9) in intact (a and c) and carious teeth (b, $d$, e, and f). While C5b-9 complex was not detected in non-carious dentin of the intact tooth (c), its labeling was intense in the carious tooth (d), and the labeling correlated to the bacterial location within the dentin tubules (e). No labeling was observed in the controls (f). (a, b) H\&E stain. (B) Immunofluorescence double-staining was used to localize C5aR- and STRO-1-expressing cells within the same tooth section. Expression of C5aR (a) and STRO-1 (c) was in the vicinity of blood vessels. Negative controls of C5aR (b) and STRO-1 (d) performed by replacement of the primary antibodies with isotype controls showed no labeling. Merged image of (a) and (c) demonstrated a co-expression of C5aR and STRO-1 in the perivascular area (e), which is clearly visible at a higher magnification ( $f$ ). Nuclei were counter-stained with DAPI (blue) (a-f). Secondary antibodies were labeled with Alexa 594 (red) to detect C5aR and Alexa 488 (green) to detect STRO-1. Symbols: arrowheads indicate caries lesions; arrows indicate C5b-9 binding of bacteria in dentin tubules; asterisk indicates reparative dentin. Scale bars: Aa-d, $f=500 \mu \mathrm{m}, A e=20 \mu \mathrm{m}$; Ba-f $=50 \mu \mathrm{m}$.

\section{MATERIALS \& METHODS}

\section{Materials}

Cell culture materials and reagents were obtained from PAA Laboratories (Les Mureaux, France). Antibodies to STRO-1, $\mathrm{C} 5 \mathrm{aR}$, and $\mathrm{C} 5 \mathrm{a}$ as well as recombinant $\mathrm{C} 5 \mathrm{a}$ were obtained from R\&D Systems (Lille, France). C5b-9 antibody and all isotype controls were obtained from Abcam (Paris, France). Secondary antibodies were obtained from Invitrogen (Saint-Aubin, France). Chemicals were obtained from Carlo-Erba (Val-de-Reuil, France).

\section{Molar Teeth Collection}

Human immature third molars, freshly extracted for orthodontics reasons, and carious teeth were obtained in compliance with French legislation (informed patients' consent and institutional review board approval of the protocol used). Teeth were fixed and routinely processed as described (Téclès et al., 2005).

\section{Immunohistochemistry}

Before teeth were stained, antigen retrieval was performed at $98^{\circ} \mathrm{C}$ for $30 \mathrm{~min}$ in $1 \mathrm{mM}$ Tris $/ 0.1 \mathrm{mM}$ EDTA $/ 0.5 \%$ Tween.
Tooth sections from intact and carious teeth were incubated for $1 \mathrm{hr}$ at room temperature with rabbit anti-human C5b-9 $\operatorname{IgG}(50$ $\mu \mathrm{g} / \mathrm{mL}$ ) or control $\mathrm{IgG}$. Immunostaining was done with a labeled streptavidin-biotin kit according to the manufacturer's instructions (Dako, Carpinteria, CA, USA). Some sections were hematoxylin-eosin-stained.

\section{Primary Pulp Cell Cultures}

Human pulp cells were prepared from immature third molars at the $2 / 3$ root formation stage by the explant outgrowth method (About et al., 2000). The teeth were obtained from three different donors for each experiment (4 molars/donor).

\section{Magnetic Cell Sorting}

Pulp progenitor cells were directly sorted from pulp cell cultures at passages 1 to 5 with mouse anti-human STRO-1 IgM with immune magnetic beads according to the manufacturer's protocol (Dynal, Oslo, Norway). After cell-sorting, each of the following experiments was performed in triplicate on the same passage (2-6) on STRO-1-sorted cells vs. unsorted pulp cells. 

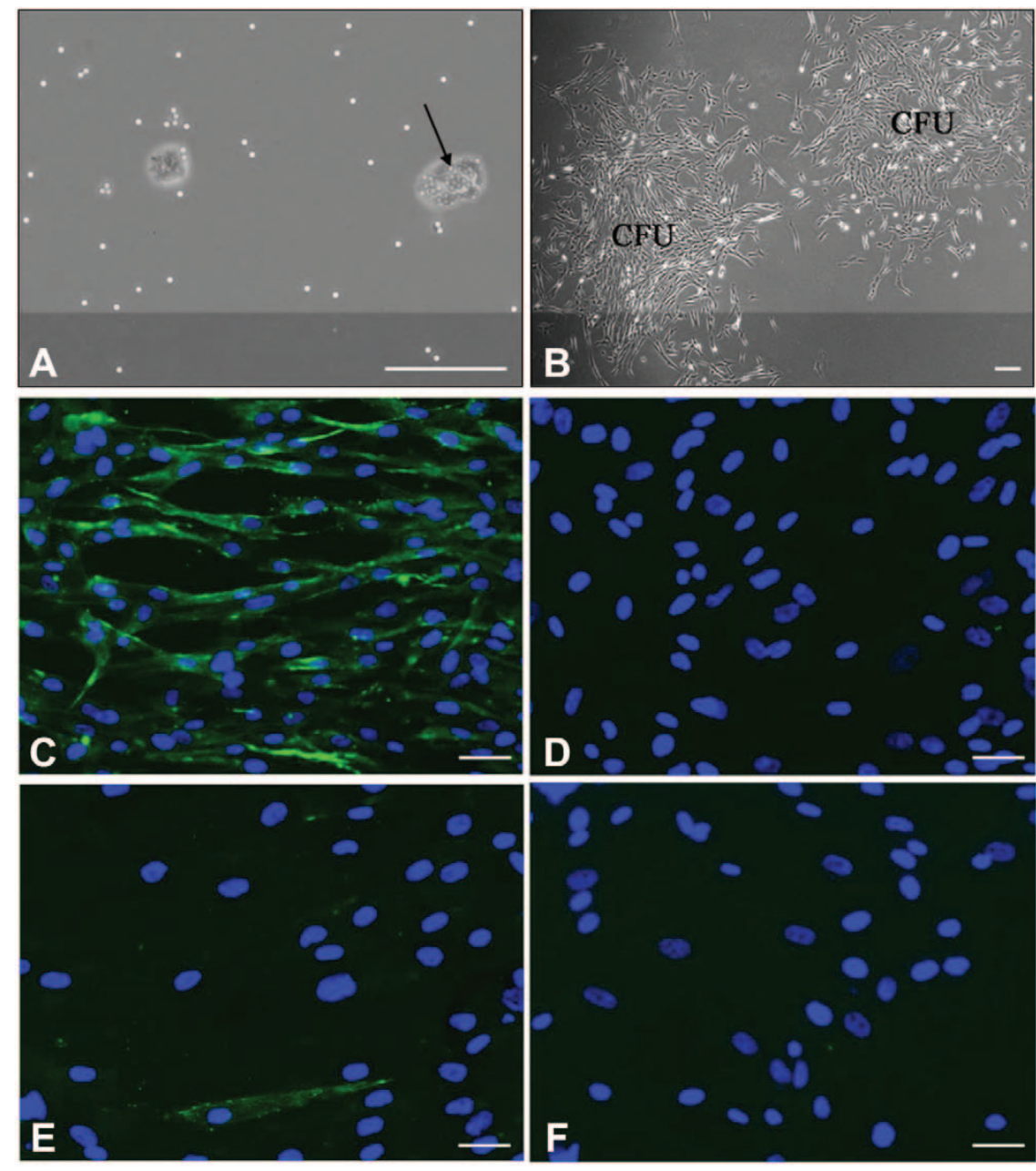

Figure 2. Efficiency of magnetic pulp progenitor STRO-1-sorted cell sorting. Human dental progenitor pulp cells were isolated from human pulp cell cultures by magnetic activated cell sorting (MACS) with STRO-1 antibody. Sorted cells were attached to the magnetic beads (arrow) (A). Small colonies characteristic of highly proliferative progenitor cells (CFU) became clearly distinguishable after 4 days (B). To confirm sorting efficiency, we immunostained STRO1-sorted and unsorted pulp cells with mouse anti-human STRO-1, followed by Alexa 488 anti-mouse lgM (green). STRO-1 was expressed in all STRO-1-sorted cells (C), whereas its expression was seen in only a very few unsorted cells $(\mathbf{E})$. The negative controls (D and $\mathbf{F}$ ) were performed by replacement of the primary antibodies with isotype controls on STRO-1sorted (D) and unsorted (F) cells, respectively. Nuclei were counter-stained with DAPI (blue) (C to F). Scale bars $=50 \mu \mathrm{m}$.

\section{Immunofluorescence Double-staining}

STRO-1-sorted and unsorted pulp cells were grown in 8-well glass culture chambers. Subconfluent cells were fixed (3\% paraformaldehyde) for $20 \mathrm{~min}$ at $4^{\circ} \mathrm{C}$. Both cultured cells and tooth sections were incubated simultaneously with mouse anti-human STRO-1 IgM and mouse anti-human C5aR IgG $(5 \mu \mathrm{g} / \mathrm{mL})$ or control isotypes for $1 \mathrm{hr}$. Then, the samples were incubated for $1 \mathrm{hr}$ with a mix of Alexa Fluor-488 goat anti-mouse IgM, Alexa Fluor-594 goat anti-mouse IgG $(2 \mu \mathrm{g} / \mathrm{mL})$, and DAPI $(1 \mu \mathrm{g} / \mathrm{mL})$.

\section{RT-PCR}

Total RNAs were isolated from STRO-1-sorted and unsorted pulp cells by means of the PureLink RNA Mini Kit (Life
Technologies, Oslo, Norway). RNA samples $(2 \mu \mathrm{g})$ were reverse-transcribed in a Reverse Transcription AMV system (Promega, Madison, WI, USA). Primers used were: (C5aR/CD88) forward, 5'-TG CTGACCATACCCTCCTTC-3', and reverse, 5'- CCCTAACCACGGACTCT TCA-3'; and (Glyceraldehyde 3-phosphate dehydrogenase [GAPDH] as an internal control) forward, 5'-GAAGGTGAAGTT CGGAGTC-3', and reverse, 5'- GAAG ATGGTGATGGGATTTC-3'. PCR conditions were: $95^{\circ} \mathrm{C} 5 \mathrm{~min}\left(95^{\circ} \mathrm{C} 30 \mathrm{sec}\right.$, $\left.55^{\circ} \mathrm{C} 30 \mathrm{sec}, 72^{\circ} \mathrm{C} 45 \mathrm{sec}\right) \times 30$, and $72^{\circ} \mathrm{C}$ $12 \mathrm{~min}$. PCR products were separated onto $1 \%$ agarose gels.

\section{C5a/C5aR Binding}

STRO-1-sorted and unsorted pulp cells were seeded overnight at $8 \times 10^{3}$ cells/ well on 96-well microplates for enzymatic detection of $\mathrm{C} 5 \mathrm{a}$ binding or in 8-well glass culture chambers for $\mathrm{C} 5 \mathrm{a}$ binding detection by immunofluorescence. Both cell types were incubated with or without C5a (10 ng/mL) for 5 min. In parallel, both cell types were also pre-incubated for $5 \mathrm{~min}$ with or without $10 \mathrm{nM}$ of W54011, a specific C5aR antagonist (Merck, Darmstadt, Germany) (Monk et al., 2007). After being washed, cells were fixed (3\% paraformaldehyde, $20 \mathrm{~min}$ ) and saturated (5\% BSA, $1 \mathrm{hr}$ ). For C5a enzymatic detection, the fragment binding was visualized by biotinylated mouse anti-human C5a IgG $(2 \mu \mathrm{g}$ / $\mathrm{mL}, 2 \mathrm{hrs}$ ) followed by Streptavidin-HRP (20 min) and substrate solution (20 $\mathrm{min})$ (R\&D Systems, Lille, France). Optical densities were measured at $650 \mathrm{~nm}$. C5a binding was calculated as the difference between the optical density with and that without C5a.

For immunofluorescence analysis, STRO-1-sorted cells were incubated with mouse anti-human C5a $\operatorname{IgG}(1 \mu \mathrm{g} / \mathrm{mL}, 1 \mathrm{hr})$. Then, the samples were incubated with Alexa Fluor-594 goat anti-mouse $\operatorname{IgG}(2 \mu \mathrm{g} / \mathrm{mL})$ and DAPI (1 hr).

\section{Chemotaxis Assays}

Migration of STRO-1-sorted and unsorted pulp cells was analyzed by live cell tracking in chemotaxis 3D-chambers (IBIDI, Marne-la-Vallée, France). These are made of 2 reservoirs separated by a thin central connecting slit (CS). The architecture and dimensions of this chamber generate a linear and stable concentration gradient by diffusing the chemotactic factor within the CS over at least $48 \mathrm{hrs}$ (Zengel et al., 2011). The cells $\left(2.5 \times 10^{6}\right.$ cells $/ \mathrm{mL}$ ) were seeded in the CS according to the manufacturer's 
A
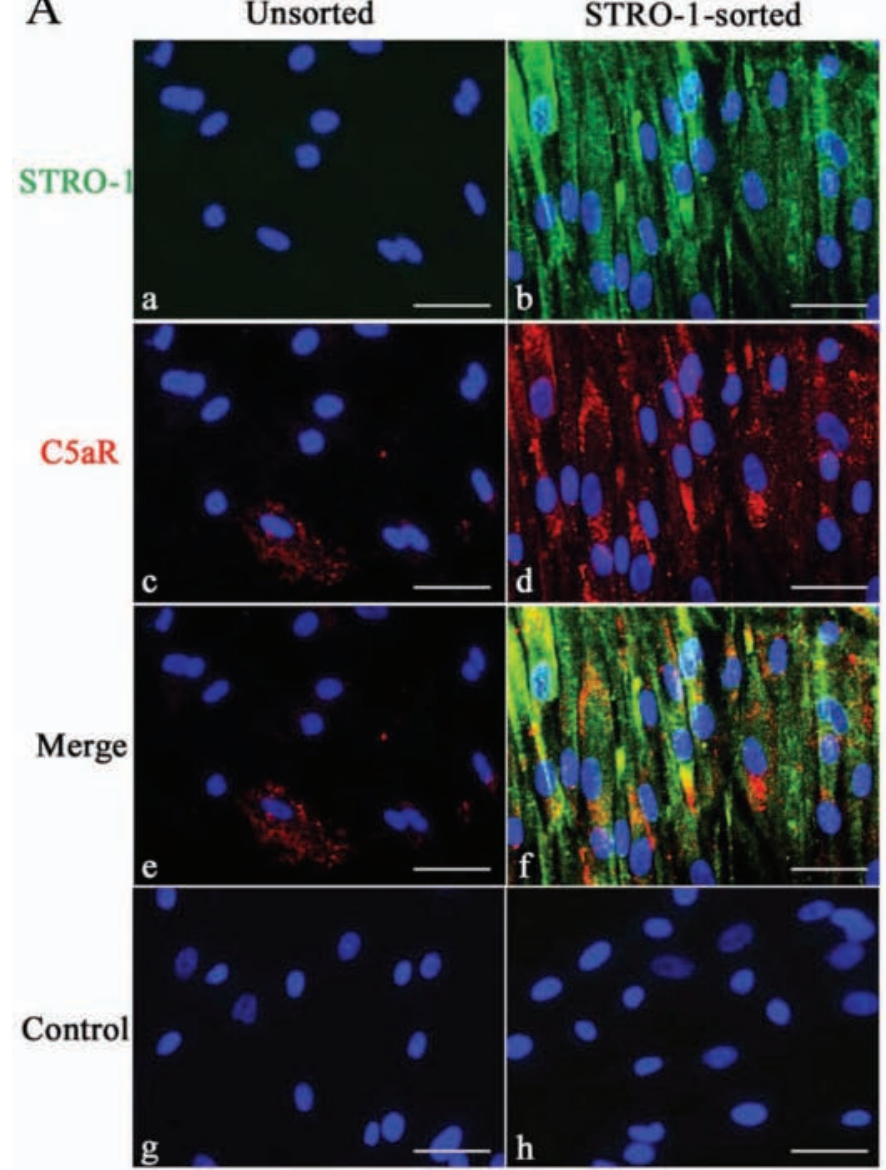

B
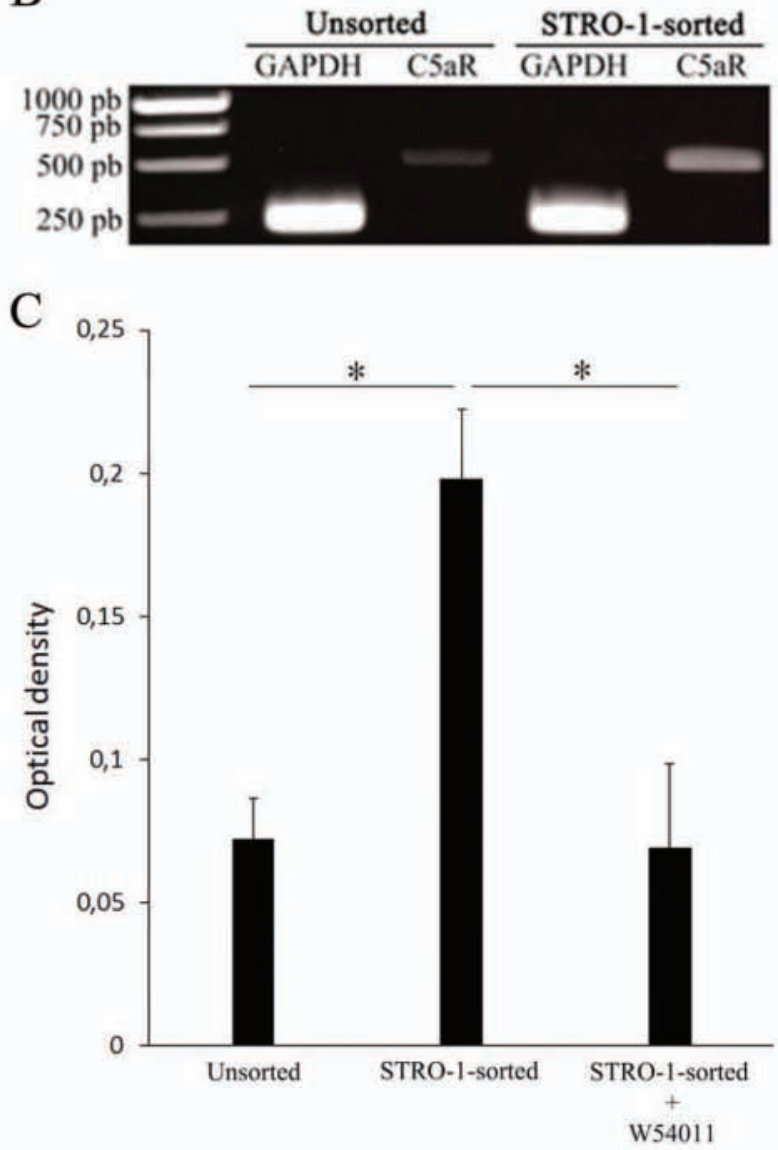

\section{D}

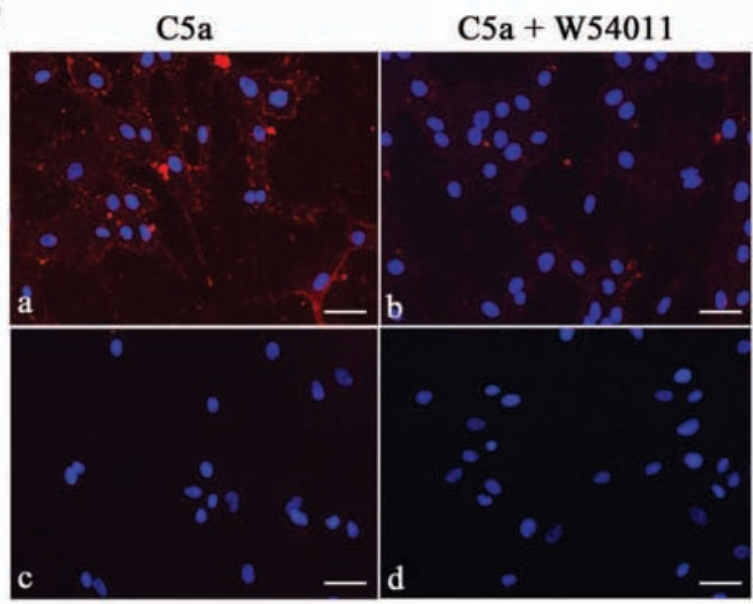

Figure 3. Expression of $\mathrm{C} 5 \mathrm{aR}$ by pulp progenitor STRO-1-sorted cells. (A) Immunofluorescence double-staining was used to analyze C5aR expression on STRO-1-sorted and unsorted pulp cells. While STRO-1 was not expressed on unsorted cells (a), this surface marker was expressed by all STRO-1-sorted cells (b). Similarly, while only a few unsorted cells showed expression of C5aR (c), all STRO-1-sorted cells appeared to express C5aR (d). Merged images of STRO-1 and C5aR revealed that some unsorted cells expressed the C5aR (e), while STRO-1-sorted cells co-expressed both STRO-1 and C5aR ( $f$ ). No immunostaining was observed, with the negative controls performed by replacement of the primary antibodies with isotype controls on unsorted (g) or on STRO-1-sorted cells (h). Secondary antibodies used to detect STRO-1 were Alexa 488 (green), while C5aR detection was done with Alexa 594 (red). Nuclei were counter-stained with DAPI (blue) (a-h). Scale bars $=50 \mu \mathrm{m}$. (B) RT-PCR analysis of C5aR/CD88 mRNA expression levels in STRO-1-sorted cells and unsorted cells. STRO-1-sorted cells had a higher C5aR expression level than did unsorted cells. GAPDH was used as a housekeeping control. (C) C5a fixation was determined by an enzymatic reaction of direct C5a binding on the cell surface. For each population, the optical density difference is represented between the cells incubated with and those incubated without C5a. The fixation of C5a on STRO-1-sorted cells was significantly higher $(p<.05)$ than its fixation on unsorted cells (asterisk). Pre-incubation of STRO-1-sorted cells with the C5aR-specific antagonist W54011 significantly inhibited its binding. Results are expressed as mean \pm SEM from at least 3 independent experiments for each cell population. (D) Immunofluorescence analysis confirmed C5a binding on STRO-1-sorted cells (a). Pre-incubation with the C5a antagonist W54011 inhibited C5a binding on the cells via the C5aR (b). No C5a binding was observed in the isotype controls (c and $d$ ). 
protocol. A gradient of chemoattractant was then created in CS by the application of C5a-containing MEM $(200 \mathrm{ng} / \mathrm{mL})$ in the first reservoir and MEM in the second reservoir. Controls were performed with both reservoirs filled with MEM. Images were taken every $15 \mathrm{~min}$ over $48 \mathrm{hrs}$. Migrations of 50 cells were analyzed/experimented with IBIDI chemotaxis and a migration tool.

\section{Statistical Analysis}

To determine statistical significance, we performed analysis of variance (ANOVA) tests using Statview software. A $p$ value of $<.05$ was considered statistically significant.

\section{RESULTS}

\section{Complement Activation in vivo}

Binding of C5b-9 to a caries-affected tooth (Figs. 1Ab and 1Ad) but not a healthy tooth (Figs. 1Aa and 1Ac) clearly demonstrated complement activation in vivo. While the labeling was intense in carious dentin (Fig. 1Ad), it was absent in non-carious dentin of the intact tooth (Fig. 1Ac). The intense labeling correlated to the presence of bacteria infiltrating the dentin tubules (Fig. 1Ae).

\section{Expression of STRO-1 and C5aR in Human Dental Pulp}

C5aR and STRO-1 were observed mainly in the vascular area (Figs. $1 \mathrm{Ba}$ and $1 \mathrm{Bc}$ ). Merged images show that not only were STRO-1 and C5aR located in the same perivascular area (Fig. $1 \mathrm{Be}$ ), but also they were co-expressed by the same cells (Fig. 1Bf).

\section{Pulp Progenitor STRO-1-sorted Cells Express C5aR}

Immediately after being sorted, all obtained cells were attached to magnetic beads linked to STRO-1 (Fig. 2a). After 4 days of culture, these cells formed colonies (CFU) characteristic of progenitor cells (Fig. 2b). After the bead-bound cells were expanded, all expressed the STRO-1 mesenchymal stem cell marker (Fig. 2c). Expression of STRO-1 was either lacking or detected in a very few unsorted cells (Fig. 2e).
Immunofluorescence double-staining confirmed STRO-1 expression on STRO-1-sorted cells (Figs. 3Aa and 3Ab). Similarly, while only a few unsorted cells showed C5aR expression (Fig. 3Ac), all STRO-1-sorted cells expressed C5aR (Fig. 3Ad), as confirmed on STRO-1 and C5aR merged images (Fig. 3Af). RT-PCR analysis revealed that STRO-1-sorted cells had a higher C5aR/CD88 mRNA level than did unsorted cells (Fig. 3B).

\section{Specific C5a Binding on C5aR of Pulp Progenitor STRO-1-sorted Cells}

C5a binding on STRO-1-sorted cells was significantly higher than that on unsorted cells. Specific binding of the peptide to C5aR on STRO-1-sorted cells was reflected by a significant decrease upon pre-incubation of the cells with the C5aR-specific antagonist W54011 (Fig. 3C). C5a-specific binding on STRO-1sorted cells was also confirmed by immunofluorescence analysis (Figs. 3Da and 3Db).

\section{C5a Induces Migration of Pulp Progenitor STRO-1-sorted Cells}

For quantification of cell migration in the chemotaxis chamber (Figs. 4Aa-c), STRO-1-sorted and unsorted cells were photographed in the migration setting (Fig. 4Ba). The single images at defined time points reflect the migration of both cell types in response to the $\mathrm{C} 5 \mathrm{a}$ gradient (Fig. $4 \mathrm{Bb}$ ) and were used to calculate the displacement of the center of mass (COM). The spatial average of all cell positions ( $\mathrm{x}$ and $\mathrm{y}$ coordinates) corresponds to the COM of all cells. The displacement of COM was the difference between the initial and the end COM values. Cell displacements are represented in plots by gray and magenta trajectories (Figs. 4Ca-d). Each plot corresponds to a representative experiment. In the absence of C5a (Figs. $4 \mathrm{Ca}$ and $4 \mathrm{Cb}$ ), movements of STRO-1-sorted and unsorted cells were random. This is reflected by a central position of COM (black dot). When unsorted cells were subjected to a C5a gradient (Figs. 4Bb and 4Cc; see also Appendix Video S1, Unsorted Pulp Cell Migration, found at http://jdr.sagepub.com/supplemental), cell movements were not affected, and their COM remained in the plot's central position, while, for STRO-1-sorted cells, COM sharply moved toward the

Figure 4. C5a induces a selective pulp progenitor STRO-1-sorted cell migration. (A) Schematic representations of a $\mu$-slide chemotaxis 3D-chamber (a). Two reservoirs (R1 and R2) communicate with a central connecting slit (CS). A channel along the y-axis is used to insert the cells into the CS. (b) A $\mu$-slide chemotaxis 3D-chamber cross-section: Pulp cells were seeded into the CS, and R1 and R2 are filled either with $200 \mathrm{ng} / \mathrm{mL}$ C5acontaining $(+\mathrm{C} 5 \mathrm{a})$ or $\mathrm{C} 5 \mathrm{a}$-free medium $(-\mathrm{C} 5 \mathrm{a})$. A linear and stable concentration gradient is generated inside the CS for 48 hrs. (c) A microscopic direct view of the observation area where the cell migration is followed for $48 \mathrm{hrs}$. (B) Setting and migration of unsorted and STRO-1-sorted pulp cells over a 48-hour period in response to a C5a gradient. Fifty cells per experiment were followed in the observation area indicated in (a). Images were taken every $15 \mathrm{~min}(192$ images per condition). The images in (b) were taken from a rectangle as indicated in (a). The reduced surface was randomly chosen to illustrate STRO-1-sorted and unsorted pulp cell migration. Each cell can be easily followed by a distinct color at different migration time-points. (C) Representative plots of cell migration over a 48-hour period (a to d): (a) and (c) are unsorted cells' trajectory plots; (b) and (d) are STRO-1-sorted cells' trajectory plots. (a and b) No directed migration is detected in the absence of C5a, with the COM (black dot) remaining in the middle of the plots. (c and d) When a C5a gradient is applied, no directed migration can be measured for unsorted cells (c), while STRO-1-sorted cells migrate toward the C5a gradient. The COM (black dot) is shifted toward the x-axis-positive direction (d). Analysis of the center of mass displacement (COM) (e and f): Graphs representing the COM $x$ and $y$ mean $(n=3)$ for each chemotaxis assay show that all unsorted cell COMs are close to $0 \mu \mathrm{m}$, reflecting random cell movement (e). In the presence of C5a, only COMx of STRO-1-sorted cells showed a statistically significant displacement (f). (D) This histogram reveals that the FMlx is significantly higher than FMly, indicating that STRO-1-sorted cells respond and migrate in function of a C5a gradient. 
A

a

$\mu$-slide chemotaxis chamber

b

Cross-section

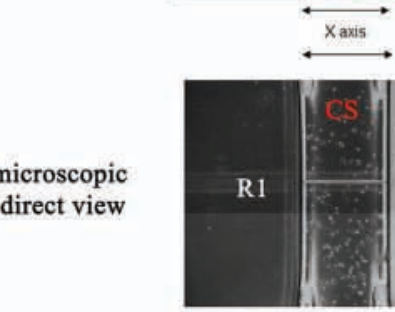

C
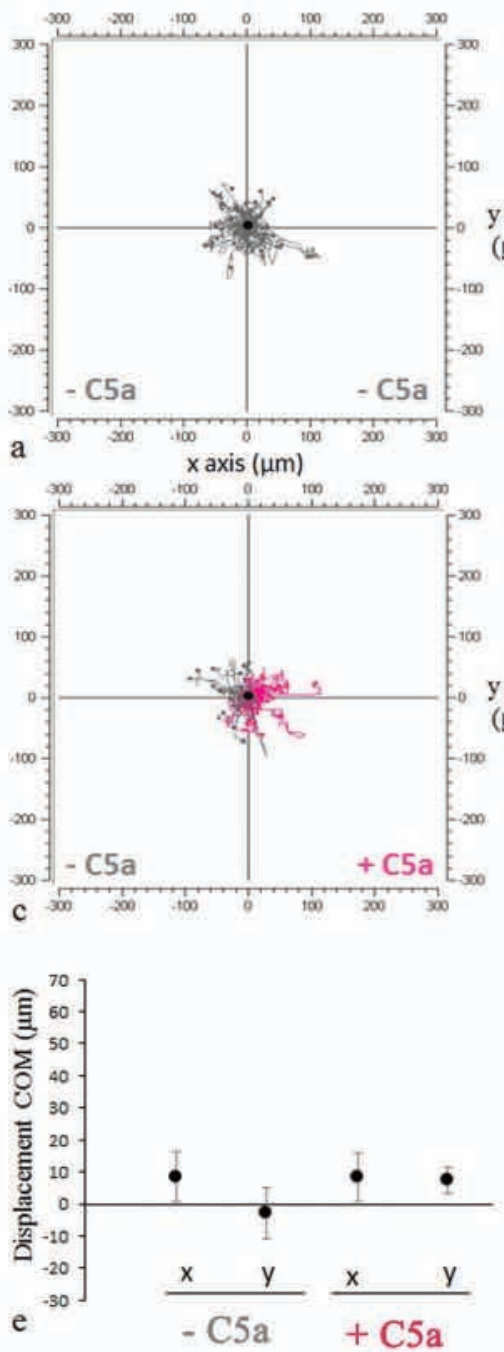

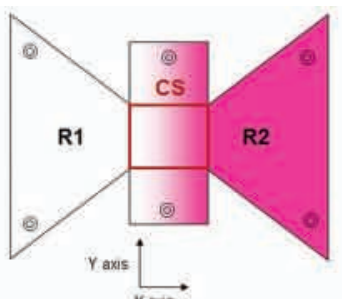

CS
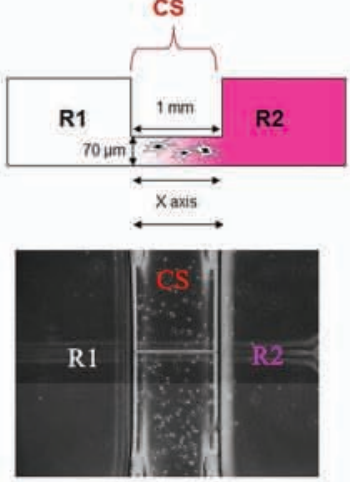

B

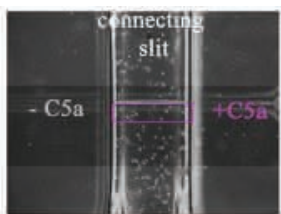

a

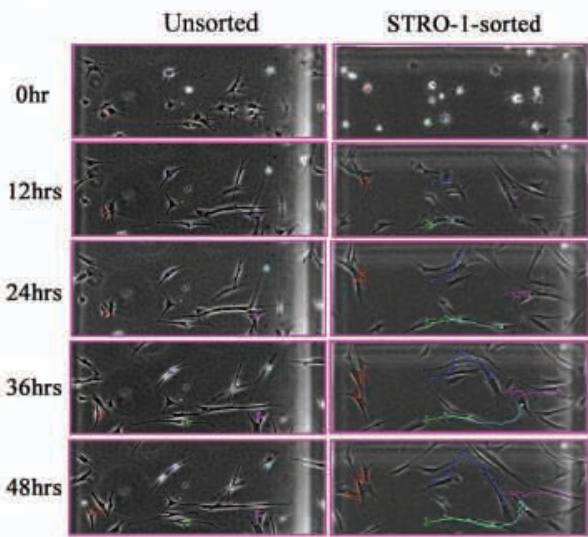

b

\section{STRO-1-sorted}

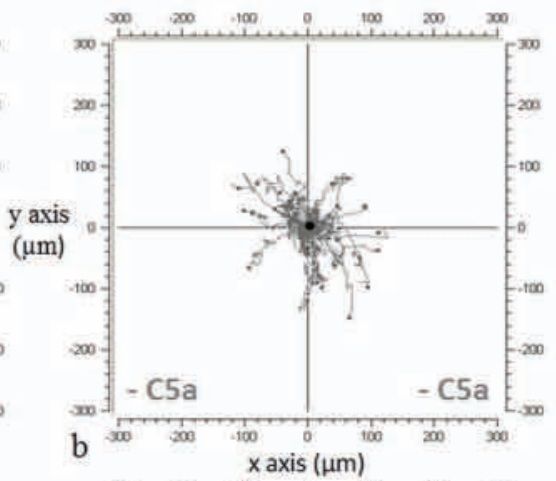

D

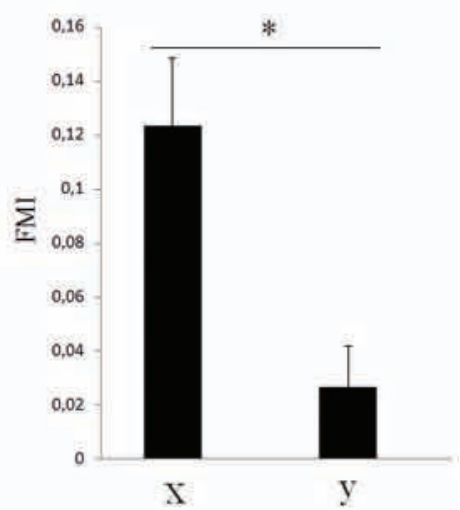


C5a reservoir (Figs. 4Ba and 4Cd; see also Appendix Video S2, STRO-1-sorted Pulp Progenitor Cell Migration, found at http:// jdr.sagepub.com/supplemental). Unsorted cell migration analysis (Fig. 4Ce) revealed no statistically significant COM displacement in $\mathrm{x}$ or $\mathrm{y}$ directions. Interestingly, migration analysis of STRO-1-sorted cells (Fig. 4Cf) showed a statistically significant shift of COM $(p<.05)$ only toward the C5a direction (without the C5a gradient, $\mathrm{x}=8.4 \pm 7.8, \mathrm{y}=-2.9 \pm 7.9$; with the C5a gradient, $x=45.6 \pm 8.9 ; y=8.9 \pm 7.7)$. Thus, C5a induces a specific and significant migration of STRO-1-sorted cells.

To determine if STRO-1-sorted cells migrate toward a C5a gradient, we investigated forward migration indices parallel (FMIx) and perpendicular (FMIy) to the gradient. FMI was calculated in $\mathrm{x}$ and $\mathrm{y}$ directions from the final end-point migration divided by the total migration distance. FMIx should be higher than FMIy if cells migrate following a gradient. As expected, the FMIx of STRO-1-sorted cells toward C5a was significantly higher than its FMIy $(p<.05)$ (Fig. 4D), indicating that the pulp progenitor cells migrate following the $\mathrm{C} 5$ a gradient.

\section{DISCUSSION}

The complement system is suggested to contribute to host defense mechanisms within the oral cavity (Boackle, 1991). Complement components, as well as activated complement fragments, have been detected in the gingival crevicular fluid (Attström et al., 1975). Analysis of our data clearly indicates that carious injuries activate complement, as revealed by the cytolytic membrane attack complex (C5b-9) formation in vivo. This activation implies $\mathrm{C} 5 \mathrm{a}$ production and provides the first demonstration of complement activation in the context of caries lesions.

The added value of our work is to show that C5a is also involved in pulp progenitor cell recruitment and that this recruitment follows a C5a gradient. This is demonstrated on tooth sections where pulp progenitor cells expressing STRO-1 in the perivascular area also express the $\mathrm{C} 5 \mathrm{aR}$. This is confirmed in vitro by RT-PCR and immunofluorescence double-staining. Analysis of our data shows that this C5aR selectively binds C5a, as demonstrated by the C5aR-specific antagonist, which inhibits C5a binding on STRO-1-sorted cells.

The expression of $\mathrm{C} 5 \mathrm{aR}$ in a few unsorted cells is beyond the scope of our project, and its detection in pulp cells is in line with previous reports showing its expression in non-inflammatory cells (Crane et al., 2009; Klos et al., 2009). However, its expression in pulp progenitor cells is an original finding. It has been established that $\mathrm{C} 5 \mathrm{a}$ acts through the $\mathrm{C} 5 \mathrm{aR}$ to enhance/maintain inflammatory responses by its chemoattractant property to polymorphonuclear neutrophils and monocytes/macrophages (Ward, 2009, 2010). C5a induces other diverse effects, such as secretion of vasoactive amines and the increase of vascular permeability, to facilitate the cells' extravascular migration (Cruvinel et al., 2010).

The pulp tissue can be altered after carious injuries due to bacterial infiltration. Our work demonstrates that this triggers complement activation. The subsequent tissue regeneration requires the migration of pulp progenitor cells and reparative dentin synthesis. Thus, the ability of progenitor cells to migrate appears as an essential function to fulfill their role in dentin regeneration at the injury site (Téclès et al., 2005). Here, we show that the pulp progenitor cells expressing $\mathrm{C} 5 \mathrm{aR}$ are responsive and migrate when subjected to $\mathrm{C} 5 \mathrm{a}$ gradient. It has been demonstrated that $\mathrm{C} 5 \mathrm{a}$ induces the migration of mesenchymal stem cells (MSC) through C5aR by a prolonged ERK1/2 phosphorylation (Schraufstatter et al., 2009). However, this phosphorylation requires binding of the $\mathrm{C} 5 \mathrm{a}$ to the target cells. In agreement with this, the direct $\mathrm{C} 5 \mathrm{a}$ binding assays and its inhibition by the specific antagonist provide clear evidence of $\mathrm{C} 5 \mathrm{a}$ binding on C5aR-expressing progenitor cells.

While little is known about the signals involved in progenitor cell migration, our findings highlight a hitherto-unexplored essential mechanism in pulp/dentin regeneration. In addition, it has been reported that $\mathrm{C} 5 \mathrm{a}$ induces a strong chemotactic activity on osteoblast and human MSCs undergoing osteogenic differentiation. This led to the conclusion that $\mathrm{C} 5 \mathrm{a}$ might play a regulatory role in bone fracture healing (Ignatius et al., 2011). Similarly, the pulp progenitor migration induction by $\mathrm{C} 5 \mathrm{a}$ is suggestive of an involvement of this molecule in damaged pulp/ dentin tissue regeneration. Our work does not exclude the involvement of other chemotactic signals. Previous works demonstrated that extracellular matrix proteins and growth factors such as transforming growth factor $\beta 1$ (TGF- $\beta 1$ ) are important promoters of pulp cell migration (Howard et al., 2010; Mathieu et al., 2013). Similar data were reported on primary pulp cell cultures with dentin and pulp matrix components (Smith et al., 2012), lipopolysaccharides (Wang et al., 2012), and stromal cell-derived factor-1 (SDF-1) (Suzuki et al., 2011). Interestingly, among the cells expressing the SDF-1 receptor, a high percentage was STRO-1-positive (Jiang et al., 2012). Our findings, demonstrating that $\mathrm{C} 5 \mathrm{a}$ induces a selective migration of progenitor cells, now connect complement activation, considered as powerful mechanism providing quick and amplified signals, to STRO-1-sorted pulp cell migration.

To our knowledge, this is the first work to demonstrate the involvement of $\mathrm{C} 5$ a biologically active fragment in the recruitment of human pulp progenitor cells connecting complement activation in caries lesions to dentin regeneration.

\section{ACKNOWLEDGMENTS}

The authors thank Dr. Jean-Charles Gardon for providing the third molars used in this work. This work was supported by funding from Aix-Marseille University, CNRS, and European Society of Endodontology through the annual research grant. The authors declare no potential conflicts of interest with respect to the authorship and/or publication of this article.

\section{REFERENCES}

About I, Bottero MJ, de Denato P, Camps J, Franquin JC, Mitsiadis TA (2000). Human dentin production in vitro. Exp Cell Res 258:33-41.

Attström R, Laurel AB, Lahsson U, Sjöholm A (1975). Complement factors in gingival crevice material from healthy and inflamed gingiva in humans. J Periodontal Res 10:19-27.

Boackle RJ (1991). The interaction of salivary secretions with the human complement system: a model for the study of host defense systems on inflamed mucosal surfaces. Crit Rev Oral Biol Med 2:355-67.

Crane JW, Baiquni GP, Sullivan RKP, Lee JD, Sah P, Taylor SM, et al. (2009). The C5a anaphylatoxin receptor CD88 is expressed in presynaptic terminals of hippocampal mossy fibres. J Neuroinflammation 6:34. 
Cruvinel Wde M, Mesquita D Jr, Araújo JA, Catelan TT, de Souza AW, da Silva NP, et al. (2010). Immune system-Part I. Fundamentals of innate immunity with emphasis on molecular and cellular mechanisms of inflammatory response. Rev Bras Reumatol 50:434-461.

Ehrnthaller C, Ignatius A, Gebhard F, Huber-Lang M (2011). New insights of an old defense system: structure, function and clinical relevance of the complement system. Mol Med 17:317-319.

Fitzgerald M, Chiego DJ, Heys DR (1990). Autoradiographic analysis of odontoblast replacement following pulp exposure in primate teeth. Arch Oral Biol 35:707-715.

Gronthos S, Brahim J, Li W, Fisher LW, Cherman N, Boyde A, et al. (2002). Stem cell properties of human dental pulp stem cells. $J$ Dent Res 81:531-535.

Howard C, Murray PE, Namerow KN (2010). Dental pulp stem cell migration. J Endod 36:1963-1966.

Ignatius A, Ehrnthaller C, Brenner RE, Kreja L, Schoengraf P, Lisson P, et al. (2011). The anaphylatoxin receptor C5aR is present during fracture healing in rats and mediates osteoblast migration in vitro. $J$ Trauma 71:952-960.

Inoue T, Shimono M (1992). Repair dentinogenesis following transplantation into normal and germ-free animals. Proc Finn Dent Soc 88(Suppl 1):83-94.

Iohara K, Zheng L, Wake H, Ito M, Nabekura J, Wakita H, et al. (2008). A novel stem cell source for vasculogenesis in ischemia: subfraction of side population cells from dental pulp. Stem Cells 26:2408-2418.

Jiang L, Peng WW, Li LF, Yang Y, Zhu YQ (2012). Isolation and identification of CXCR4-positive cells from human dental pulp cells. J Endod 38:791-795.

Klos A, Tenner AJ, Johswich KO, Ager RR, Reis ES, Köhl J (2009). The role of the anaphylatoxins in health and disease. Mol Immunol 46:2753-2766.

Mathieu S, Jeanneau C, Sheibat-Othman N, Kalaji N, Fessi H, About I (2013). Usefulness of controlled release of growth factors in investigating the early events of dentin-pulp regeneration. $J$ Endod 39:228-235.

Mitsiadis TA, De Bari C, About I (2008). Apoptosis in developmental and repair-related human tooth remodeling: a view from the inside. Exp Cell Res 314:869-877.

Monk PN, Scola AM, Madala P, Fairlie DP (2007). Function, structure and therapeutic potential of complement $\mathrm{C} 5 \mathrm{a}$ receptors. Br J Pharmacol $152: 429-448$
Schraufstatter IU, Discipio RG, Zhao M, Khaldoyanidi SK (2009). C3a and C5a are chemotactic factors for human mesenchymal stem cells, which cause prolonged ERK1/2 phosphorylation. J Immunol 182:3827-3836.

Shi S, Gronthos S (2003). Perivascular niche of postnatal mesenchymal stem cells in human bone marrow and dental pulp. $J$ Bone Miner Res 18:696-704

Sloan AJ, Smith AJ (1999). Stimulation of the dentine-pulp complex of rat incisor teeth by transforming growth factor-beta isoforms 1-3 in vitro. Arch Oral Biol 44:149-156.

Smith AJ, Tobias RS, Cassidy N, Plant CG, Browne RM, Bégue-Kirn C, et al. (1994). Odontoblast stimulation in ferrets by dentine matrix components. Arch Oral Biol 39:13-22.

Smith JG, Smith AJ, Shelton RM, Cooper PR (2012). Recruitment of dental pulp cells by dentine and pulp extracellular matrix components. Exp Cell Res 318:2397-2406.

Suzuki T, Lee CH, Chen M, Zhao W, Fu SY, Qi JJ, et al. (2011). Induced migration of dental pulp stem cells for in vivo pulp regeneration. J Dent Res 90:1013-1018.

Téclès $\mathrm{O}$, Laurent $\mathrm{P}$, Zygouritsas $\mathrm{S}$, Burger AS, Camps J, Dejou J, et al. (2005). Activation of human dental pulp progenitor/stem cells in response to odontoblast injury. Arch Oral Biol 50:103-108.

Téclès O, Laurent P, Aubut V, About I (2008). Human tooth culture: a study model for reparative dentinogenesis and direct pulp capping materials biocompatibility. J Biomed Mater Res B Appl Biomater 85:180-187.

Tsuji T, Takei K, Inoue T, Shimono M, Yamamura T (1987). An experimental study on wound healing of surgically exposed dental pulps in germfree rats. Bull Tokyo Dent Coll 28:35-38.

Wang MC, Hung PS, Tu HF, Shih WY, Li WC, Chang KW (2012). Lipopolysaccharide induces the migration of human dental pulp cells by up-regulating miR-146a. J Endod 38:1598-1603.

Ward PA (2009). Functions of C5a receptors. J Mol Med 87:375-378.

Ward PA (2010). Role of C5 activation products in sepsis. Scientific World Journal 10:2395-2402.

Zengel P, Nguyen-Hoang A, Schildhammer C, Zantl R, Kahl V, Horn E (2011). $\mu$-slide chemotaxis: A new chamber for long term chemotaxis studies. BMC Cell Biol 12:21. 